\title{
Ruptura en la literatura infantil: El libro triste y Humo
}

\section{Rupture in Children's Literature: The sad book and Smok}

\author{
David Fernando Torres Lizarazo \\ Magíster en Filosofía, docente cátedra \\ Universidad Industrial de Santander, Bucaramanga, Colombia \\ Correo electrónico: David.fer0712@hotmail.com \\ Iveth Paola Moreno Bernal \\ Estudiante de Maestría en Filosofía \\ Universidad Industrial de Santander, Bucaramanga, Colombia \\ Correo electrónico: Ipmb31@gmail.com
}

Recibido: 21 de septiembre de 2017. Aprobado: 9 de octubre de 2017

\section{Cómo citar este artículo}

Torres, D.F., Moreno, I.P. (2018). Ruptura en la literatura infantil: El libro triste y Humo. Espiral, Revista de Docencia e Investigación, 8(1), 31 - 41.

\section{Resumen}

Tipología y objetivo. El presente artículo de reflexión responde a la necesidad de actualizar la apreciación que aún existe en torno a la literatura infantil. A partir de los libros infantiles El libro triste (2004) y Humo (2008) y de algunos postulados acerca de la muerte en la enseñanza escolar, principalmente de Mar Cortina y Agustín de la Herrán, se mirará la reflexión que hace Marisa Bortolussi (1987), en su texto Análisis teórico del cuento infantil, sobre la literatura infantil en contraste con la adulta, y los temas tabú, en los que resaltamos la muerte, que la han conformado desde su existencia. De tal forma que se propone una ruptura respecto a la visión de la literatura infantil desde una postura que limita las temáticas de sus textos, a partir de la consideración que reconoce una serie de limitaciones en la capacidad de recepción de la información por parte del infante de los textos literarios.

Metodología. Este artículo se construye a partir de la metodología de investigación documental o bibliográfica, que busca relacionar los avances tecnológicos y el acceso a la información con los cambios necesarios en las temáticas que se dan en la educación formal a partir de una concepción actualizada de los intereses argumentales en los que se desenvuelve la literatura infantil.

Palabras clave: Enseñanza, literatura infantil, muerte, recepción, tabú, TIC.

\begin{abstract}
This reflex article responds to the necessity of update the assessment that still exists around children's literature. From the children's books El libro triste (2004) and Humo (2008) and from some postulates about death in school education, mainly from Mar Cortina and Agustín de la Herrán, it will look at the reflection that Marisa Bortolussi makes (1987), in her text Análisis teórico del cuento infantil, about children's literature, in contrast to the adult one, and the taboo, in which we highlight death, subjects that have shaped it since its existence. In such a way that a break about the vision of children's literature is proposed from a position that limits the thematics of their texts, from the consideration that recognizes a series of limitations in the capacity of reception of information by the infant of literary texts.

Methodology. This article is built from the methodology of documentary or bibliographic research that seeks to relate technological advances and access to information with the necessary changes in the topics that are given in formal education from an updated conception of the plot interests in which children's literature develops.
\end{abstract}

Keywords: Children's literature, death, education, reception, taboo, TIC. 


\section{Introducción}

Marisa Bortolussi expone sus reflexiones sobre la naturaleza de la literatura infantil en un interesante libro titulado Análisis teórico del cuento infantil. En este texto hace un recorrido por la historia de la literatura infantil, vista desde los cambios existentes en la concepción del género: desde sus incipientes inicios en los que no existía como tal una literatura infantil, demarcados en una noción de necesidad moralizante que enseñara los valores del pensamiento dominante de la época, es decir, conservadora de las tradiciones; hasta la consolidación del género, en el silo XIX, y del receptor infantil, literatura que evidencia en el niño su destinatario. Es en este siglo cuando se busca, por primera vez, hacer un análisis estructural, teórico de la literatura infantil en los cuentos de hadas. Propp, en primer lugar, y, luego, Greimas (Bortolussi, 1987) serán los pioneros en este ejercicio académico-reflexivo. Bortolussi mira con minuciosidad las reflexiones acerca de la recepción del niño y la capacidad que este tiene para la literatura infantil. No obstante, el punto que más nos interesa de Marisa Bortolussi en su Análisis es en el que hace la comparación entre el cuento infantil y el cuento adulto, apoyado en otros puntos importantes de su obra.

Este apartado nos interesa, porque nos permite hacer una profunda reflexión acerca de lo que es la literatura infantil frente a la muerte, asimismo, frente a las mass media, que han acercado al niño a diversos temas que, aun se consideran tabú. A raíz de esto, primero abordaremos esas diferencias planteadas por Bortolussi entre el cuento infantil y el cuento adulto, luego, la relación de la muerte con los mass media, para, finalmente, encontrar en los libros infantiles El libro triste y Humo una relación de ruptura con las consideraciones propuestas por Bortolossi.

\section{Desarrollo}

\section{Diferencias entre el cuento infantil y el cuento adulto según Bortolussi}

Para Bortolussi (1987) existen, de manera notoria, diferencias entre la literatura infantil y la literatura adulta que no debieran eliminarse. Por decirlo de otra manera, para Bortolussi esa línea generacional no se puede transgredir, puesto que, de esa forma, simplemente estaríamos haciendo literatura de una o de la otra, aunque creyéramos lo contrario. El cuento infantil, según el recorrido teórico histórico que realiza la autora, cuenta con unas características que lo determinan como tal. En una primera medida, el cuento infantil mantiene una visión optimista: “(...) el final siempre constituye una reintegración, una lección aprendida, una vuelta al comienzo (...)" (Bortolussi, 1987, p. 67). Como requisito, entonces, el cuento infantil debe concebir para el niño un final en donde el protagonista es recompensado o castigado, pero siempre recibido devuelta al amor y a la comprensión de la familia o de algún ser especial. El cuento infantil debe, por lo tanto: "contener un elemento de optimismo y terminar bien" (Bortolussi, 1987, p, 67). Esto permitirá que el niño lector no sucumba ante la realidad' que muchas veces absorbe al ser humano. La función del cuento infantil será más una guía por los senderos del desconsuelo, del miedo, de lo desconocido: "El cuento infantil ofrece una respuesta, una solución, una esperanza; inspira una confianza" (Bortolussi, 1987, p. 68). Para Bortolussi es claro que el cuento infantil moderno y contemporáneo funciona entonces como una respuesta positiva ante las preguntas inquietas de los niños. El cuento infantil es un padre o una madre que charla y responde tranquilamente a su hijo las dudas que este

$1 \quad$ Para Bortolussi (1987) este será un Realismo trágico y que, por lo tanto, "sería muy peligroso, pudiendo causarle -al niño- traumas insuperables" (p. 120). Estos textos, para la teórica, tendrán una "función naturalista, cuyo mundo narrativo es una mímesis de la vida real con sus problemas, y con todas las experiencias traumáticas, y las tragedias con las cuales puede encontrarse un niño: divorcio, miseria, enfermedades, etc." (Bortolussi, 1987, p. 125). 
tenga sobre las particularidades de su vida. Estas preguntas de los niños estarán alejadas, consecuentemente, de los temas tabú o que solo deben interesar a los adultos, caso el de la muerte.

Asimismo, ese padre nunca va más allá de lo que su hijo pregunta y nunca se interesa por decirle algo que escape a esa mera curiosidad, pues, según lo planteado en este aparte, el niño no tendrá los recursos psicológicos, vivenciales, morales, para tener un acercamiento adecuado a algunas temáticas, como por ejemplo la muerte:

Pero el receptor del cuento infantil, el niño, no posee ni el mismo intelecto, ni la misma capacidad de abstracción, ni la misma competencia de lector, ni la misma experiencia vivencial. Lógicamente, entonces, hay un límite de las experiencias que el cuentista que escribe para niños puede comunicar a su receptor. Creemos acertar al decir que la anécdota del cuento infantil debe poder reducirse, de alguna manera, a la experiencia directa del receptor niño. Si la anécdota va más allá de la experiencia normal del niño, no habrá identificación, y sin identificación no habrá comunicación, ni cuento infantil logrado (Bortolussi, 1987, p. 68).

Se deduce de ello, por lo tanto, que el receptor, en el cuento infantil, prima al escritor ${ }^{2}$. A diferencia, en el cuento adulto el escritor tiene la autonomía de plantear sus interrogantes y de responderse a ellos. También tiene libertad temática, de extensión, de uso de palabras tabú y de presentar, dado el caso, algunas historias con contenido muy fuerte, que serían duramente cuestionadas si fueran sucesos reales. En el cuento infantil el escritor está limitado al

2 “(...) en el cuento infantil la comunicación que se establece no es una comunicación natural, por la evidente desigualdad entre emisor 1 y 2 y receptor, es más bien una comunicación adaptada. En primer lugar, el yo emisor 1 y 2 debe, hasta cierto punto, "desnaturalizarse", en el sentido en que debe: 1) elegir una experiencia real o imaginativa que él estima decodificable por el receptor, y 2) elegir un modo especial para comunicar esta experiencia, lo cual implica una doble destrucción o modificación a nivel tanto empírico como lingüístico. El emisor del cuento infantil es entonces un yo alterado, condicionado" (Bortolussi, 1987, p. 124). lector. El lector decide qué preguntar, pero el autor debe saber qué debe escuchar este como respuesta. Recordemos: el cuento infantil es como un padre que responde a las inquietudes de su hijo.

Ahora bien, Bortolussi se basa en los planteamientos realizados, principalmente, por Piaget y Vygotsky. Observa cómo es concebida la recepción del niño y qué sería lo "más adecuado" para su capacidad receptiva. Según el nivel de recepción que tenga el niño, separado por edades, el escritor deberá hacer su obra literaria, pensar su obra literaria. Como ya hemos dicho, para ella, los parámetros de la literatura infantil nacen en el niño y el escritor debe adaptarse a ellos, lo que deja en muchas ocasiones a la muerte como un tema inadecuado de abordar, si acaso limitado a la historia de un anciano que se encuentra en el final de su existencia y que, por tanto, la muerte se vivencia como un acto natural e inevitable, fácil de explicar y de comprender.

Nos surgen, entonces, algunas preguntas ¿Qué tanto se han roto, o mejor, modificado naturalmente estos planteamientos de Bortolussi? O ¿qué tanto ha cambiado esa concepción o la mentalidad de los niños en las últimas décadas? ¿El escritor sigue pensando en su receptor infantil como alguien a quien debe dirigirse de la forma en que este lo determine? ¿El escritor de la literatura infantil hoy tiene más posibilidades de escribir para niños desde diferentes ópticas? ¿El escritor de literatura infantil aún hoy piensa que está determinado al escribir por sus posibles lectores? ¿Hay alguna ruptura o solo cambios en nuestra época que lleven a expandir temáticas y formas en la literatura infantil? No obstante, responderemos solo algunas de estas preguntas y las demás quedarán a consideración de quien desee profundizar en la literatura infantil. La transformación acerca de la apreciación de los temas tabú en esta época está muy relacionada con la evolución de la tecnología y, con ella, de los medios masivos de comunicación. Nunca antes 
el ser humano, incluidos los niños, estuvo tan cerca de todos los acontecimientos del mundo, por macabros o funestos que sean, incluso todas las posibles vertientes que tiene la muerte. En este tiempo, por tanto, los niños tienen la posibilidad de establecer nuevas formas de comprender la muerte. De ello, corresponderá el siguiente apartado.

\section{Los niños en la época de los mass media, las TIC, y una pedagogía para la muerte}

Es evidente que estamos en una época influenciada, adecuada o inadecuadamente, por los medios de comunicación y también por los avances tecnológicos de todo tipo. Pensar la vida actualmente dista en gran medida de haber pensado la vida hace unos 40 años; se nos abre un abismo insalvable si la comparáramos con una existencia antes del siglo XX. Probablemente, para la mayoría de niños, que también tienen acceso a la literatura infantil, pensar una vida sin televisión, sin computador, sin celular, sin Internet, es imposible. Por lo tanto, notamos que las investigaciones poco a poco se van inclinando a observar detenidamente la relación que sostiene el ser humano con los mass media, con la tecnología, o la relación que sostiene el hombre con el otro a través de este mundo cada vez más maquinizado. Esta evolución tecnológica y comunicativa repercute igualmente en el acto de escribir, incluso de la escritura de la literatura infantil, y amplía el espectro de recepción de temáticas por parte de los niños en la actualidad (López, 1990). La literatura infantil ha ido ampliando sus temáticas a la vez que la humanidad ha tenido acceso a múltiple información.

Asimismo, no solo la época ha cambiado la relación del hombre con el hombre, sino, a su vez, la relación del hombre con su entorno, que ahora reconoce inmensamente más amplio; la relación del hombre con el conocimiento o con la mera información, la relación del hombre con la vida y la relación del hombre con la muerte. De tal manera, el niño nace con una necesidad apremiante de incluirse, de apropiarse oportunamente de los mass media, de las TIC, que cada día surgen más rápidamente. De esta necesidad surge también una obligatoriedad de parte de la escuela para suplir los requisitos que los nuevos niños tienen acerca de la relación con la tecnología y la globalización. En palabras de Marqués (2012):

Esta emergente sociedad de la información, impulsada por un vertiginoso avance científico en un marco socioeconómico neoliberal-globalizador y sustentada por el uso generalizado de las potentes y versátiles tecnologías de la información y la comunicación (TIC), conlleva cambios que alcanzan todos los ámbitos de la actividad humana. Sus efectos se manifiestan de manera muy especial en las actividades laborales y en el mundo educativo, donde todo debe ser revisado: desde la razón de ser de la escuela y demás instituciones educativas (...) (p. 3).

En efecto, vemos a los niños desde pequeños sumergidos en la televisión, en el Internet, en el cine, en el celular, en la tablet. A sus padres presurosos de inculcarles el uso apropiado o de capacitarlos acertadamente en la búsqueda real de información. A los profesores mayores de las diferentes escuelas capacitándose en un medio que desconocieron en su infancia y a los más jóvenes crear didácticas, acordes con los lineamientos educativos de cada país, para el correcto desarrollo del conocimiento y de la identidad en un mundo cada vez más sistematizado y construido entre información relevante e irrelevante.

Se crean, a raíz de ello, nuevas estrategias, métodos de enseñanza/aprendizaje (Marqués, 2012, p. 4) que busquen una alfabetización digital y que los niños, jóvenes y adultos, empleen adecuadamente las herramientas de búsqueda de conocimiento que tienen al alcance de su mano. ¿Cuál es la intención? ¿Cómo vemos los niños en la época de las mass media, de las TIC? El niño, desde muy temprana edad, tiene a su servicio información relevante, que se busca 


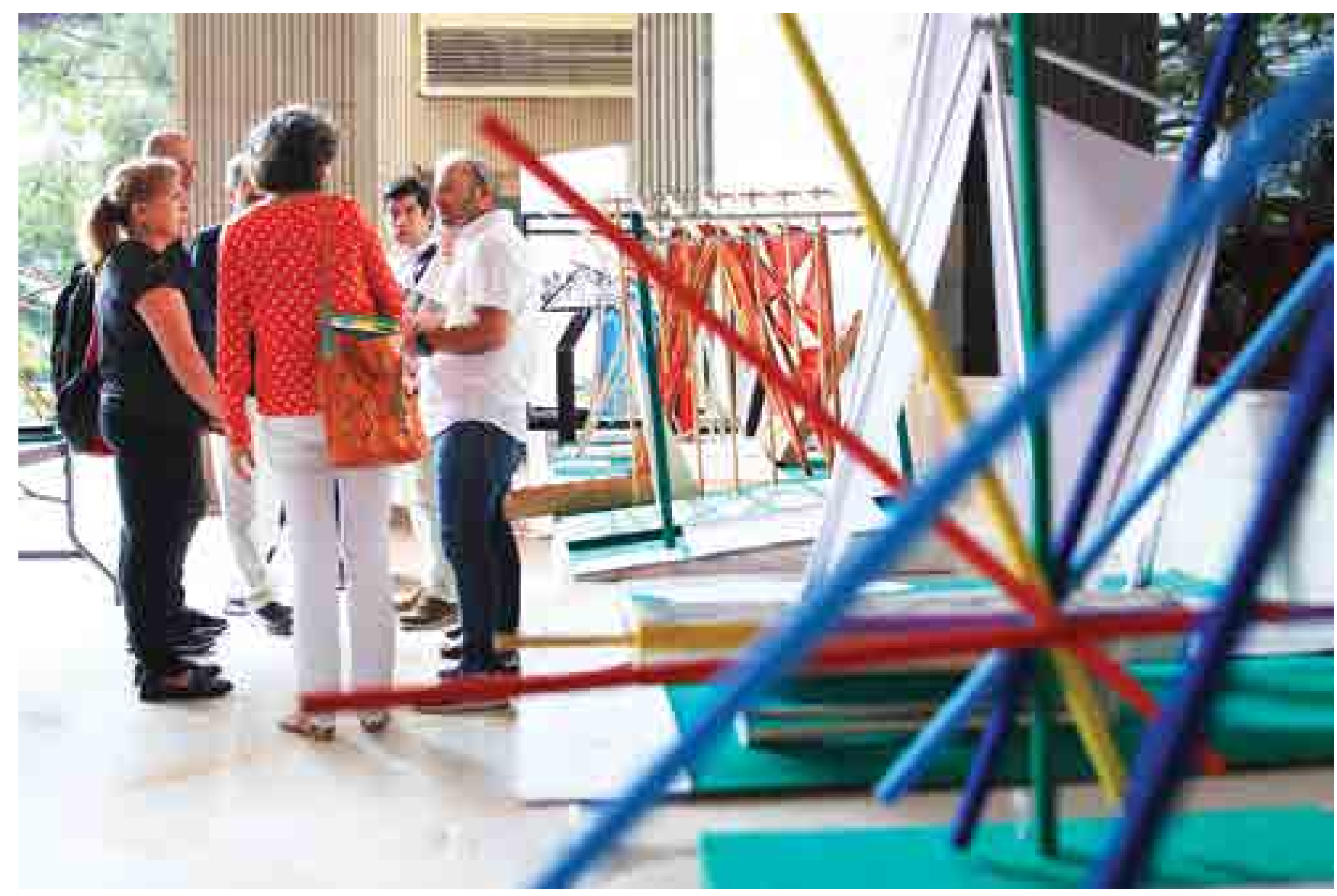

explotar en la escuela, pero también información irrelevante, malévola, fuerte, insustancial, que, de igual forma, puede llegar a influenciar en sus vidas. Los niños pueden llegar a saber de la misma manera sobre adelantos tecnológicos, científicos, sociales, de las vacuidades, miedos, rencores, amores personales, propios e impropios (de las redes sociales), que de las guerras, de las muertes lejanas y cercanas, de las violaciones, de las perversiones, de la imaginación afortunada o desafortunada, etc., a través de las mismas herramientas.

Un niño puede perder ingenuidad a medida que las puertas del mundo se le van abriendo a sus ojos. De tal suerte que ya no parece suficiente solo educar en lo que se ha educado tradicionalmente, sino que se hace necesario educar al niño en lo que hace unos siglos se consideraba que debía desconocer, pero que en la actualidad es muy posible que reconozca en su contexto cotidiano, como las guerras, o también en lo que se les presenta intempestivamente por algún medio diferente a la escuela o el hogar, caso tal de la muerte a cualquier edad de algún familiar cercano y querido:

El conjunto de transformaciones socioculturales de las últimas dos décadas obliga a ver, a pensar, a hablar y a actuar sobre la infancia de manera diferente. La concepción tradicional de la niñez como una etapa de la vida caracterizada por la inocencia y la fragilidad, ha venido dando paso a miradas más abiertas que reconocen los derechos, la autonomía, la independencia y participación de los niños y niñas en sus procesos de desarrollo y formación. Esto se ha dado en gran parte por la presencia de los medios de comunicación y las nuevas tecnologías en sus vidas cotidianas, en tanto les han permitido acceder al conocimiento por vías diferentes a las de sus referentes tradicionales de formación, como han sido sus madres, sus padres, sus maestras y sus maestros. Así mismo, 
los medios han contribuido a crear nuevas formas de socialización y constitución de la subjetividad de los niños y las niñas (Duarte, 2013, p. 462). Es decir, una tenue línea se va borrando. Al menos en cuanto a la información que se sabe cercana y de fácil acceso una diferencia se va desdibujando del plano social. Tanto niños y adultos pueden acceder a la misma información, adecuada o inadecuada, y pueden construir en torno de ella su mundo:

En la investigación genealógica sobre la niñez, citada por Grieshaber y Cannella (2005), se cuestiona la suposición de que la niñez es algo ajeno y totalmente distinto a la edad adulta. Las autoras afirman que "Los discursos sobre la niñez han fomentado la idea de que un grupo de individuos debe ser regulado por otro grupo (descrito como el de los adultos) y han generado múltiples espacios de poder en beneficio de esos adultos" (pp. 26-27). Señalan, además, para refutar esta premisa moderna, cómo algunas investigaciones han mostrado que los niños y niñas, aún los más pequeños, tienen mayor control del que tradicionalmente se ha supuesto sobre los asuntos que les afectan sus cuerpos, mentes y vidas (Leavitt, 1994, citado por Grieshaber \& Cannella, 2005, p. 27).

Los fenómenos indicados anteriormente, son referidos por la antropóloga Mead (1997), citada por Martín-Barbero (1996, p. 14), cuando afirma que en la cultura contemporánea los aprendizajes y formas del vínculo social de los niños, niñas y jóvenes, dependen menos que antes de las personas adultas, pues han logrado mayores grados de autonomía en sus formas de explorar el mundo, de socializarse y de educarse (Duarte, 2013, p. 462).

Podemos estar de acuerdo o no, en su totalidad, pero sí es importante reconocer que esa frontera, aunque desde la declaración de los derechos de los niños en 1959 (Corte Constitucional, 2015) pareciera establecerse como infranqueable, se ha visto vulnerada por los cambios tan abruptos que ha sufrido la sociedad en las últimas décadas. Cabe aclarar que no podemos decir que los derechos de los niños han sido atacados; no podemos decir que, por ejemplo, el hecho de que hoy un niño tenga acceso a mucha más información, que en su momento fuera considerada inadecuada, implique un desarrollo no saludable en su concepción psíquica y moral. No obstante, sí afirmamos que se han transformado actitudes, formas de actuar entre niños y adultos. También habrán cambiado las preguntas que los niños hacen y las formas en que los profesores enseñan en las escuelas, puesto que la globalidad permite que nos apropiemos de información que antes era desconocida para la mayoría.

Uno de los temas que cada vez se acerca más a la realidad del niño es la muerte ${ }^{3}$. Reconocerse como un ser destinado a morir y reconocer la muerte de los otros es más 'simple' en la actualidad para un niño. Noticieros, periódicos (amarillistas), Internet, radio, televisión, cine, el boca a boca de nuestros barrios, la muerte de algún ser querido, de un amigo, de un compañero de escuela, la propia cercanía a la muerte, permiten al niño preguntarse y preguntar por ella. Pero también los mismos medios le permiten, sin mediación alguna, saber y tener respuestas, acertadas o no, de la misma muerte. La escuela ha visto la necesidad de educar sobre o para la muerte, no como mero suceso biológico, que puede verse en ciencias naturales, o como camino a un más allá o reencarnación, como puede enseñarse en áreas afines a la religión, sino como un suceso que tiene diversas afectaciones en el ser humano, diversos ritos, diversos acercamientos, también implicaciones sociales, morales, políticas, económicas, etc. Mar Cortina, a veces junto a Agustín de la Herrán ${ }^{4}$, tiene

3 Ya a mediados del siglo pasado para Aranguren la muerte era un tema que se consideraba tabú, en los adultos, y que se veía replanteado, aunque sin dejar ese estado de tabú: "Hubo una época, todavía no lejana, en que se consideraba de mal gusto, incluso intelectual y literario, hablar de la muerte. Hoy ocurre lo contrario. Pero la muerte puede ocultarse tanto silenciándola como hablando de ella" (Aranguren, 1985, p. 301). Es evidente que el planteamiento de Aranguren se vería totalmente renovado en esta época determinada por los mass media y las TIC.

4 Uno de sus libros más importantes es: La muerte y su didáctica: manual para educación infantil, primaria y secundaria. 
una serie de textos destinados a la enseñanza o a la orientación que debemos tener con el otro o el otro con nosotros mismos en la muerte.

Para estos dos pensadores, la muerte, a pesar de que la vemos en todo lado a toda hora, se convirtió en un tema cada vez más desagradable, en un tabú ${ }^{5}$ diferente:

La muerte es el tema constantemente vetado. Es negativo, de mal gusto. Al muerto se le encajona, se le acristala, se le tapa, se le camufla con flores y olores tan significativos que cuesta olvidar. Así, se le relega y se le aparta, se le desintegra de la familia, con frecuencia, precipitadamente. A diferencia de otros entornos socioculturales, en el nuestro -al menos desde Napoleón y por motivos de salud e higienelos cementerios también se han alejado de los centros de las ciudades (Cortina y de la Herrán, 2007, p. 1).

Como habíamos mencionado antes, se convierte poco a poco en una necesidad, debido a la globalidad de nuestra sociedad, replantearse los sistemas educativos, los temas educativos y las necesidades estudiantiles. Desde ese punto de vista aún falta mucho para superarlo, porque se entiende que no estamos en capacidad de hacerlo. Si los adultos no hemos aprendido a afrontar la muerte, es difícil considerar o creer que un niño pueda hacerlo: "(...) pareciera que el tabú de la muerte es un tabú de segundo nivel, más difícil de satisfacer para el niño, en la medida en que el adulto medio está muy lejos de superarlo" (Cortina y de la Herrán, 2007, 1). Sin embargo, ellos son conscientes de que cada día se hace más imperante una educación sobre la muerte. Nuestro mundo de mass medias, de TIC, de sucesos rápidos, fugaces, no nos deja mucho margen de toma de decisiones. Por lo tanto, ellos consideran adecuado unas didácticas y unos fundamentos que queden para siempre marcados en los diferentes currículos

5 Como ya vimos, para Aranguren nunca ha dejado de ser tabú, aunque de formas diferentes. o lineamientos de cada docente e institución. En efecto:

Es una apertura para la formación, que se apoya y construye desde la muerte como un ámbito de extraordinario potencial formativo. Es un camino para conectar la educación ordinaria con la Educación de la Conciencia, una rama de este árbol mayor. Desde ella se intentan dar pistas para replantear el sentido de lo que hacemos, tanto en la comunicación didáctica cotidiana como en los momentos en que debemos ayudar a asumir una muerte cercana (Cortina y de la Herrán, 2008, p. 3).

A pesar de que queda mucho camino por recorrer, para Cortina y de la Herrán, es latente la importancia de una educación sobre la muerte, y parece necesaria sobre todo porque esta época en que vivimos nos ha llevado a estar mucho más cerca, de muchas perspectivas, de ella.

Ahora bien, Marisa Bortolussi no pudo concebir en su Análisis teórico del cuento infantil el proceso de transformación social que otorgarían los mass medias y las TIC al hombre. No podemos ser los mismos que hace 28 años. Al igual que para 1987 la literatura infantil ya no era la misma que la del siglo anterior. Sin embargo, nos preguntamos ¿Cuál es la ruptura, si existe, de la literatura infantil actual a las reflexiones de Marisa Bortolussi en su Análisis teórico del cuento infantil?

\section{El libro triste y Humo}

Las apreciaciones expuestas por Mar Cortina y Agustín de la Herrán adquieren relevancia, por ejemplo, en el ámbito literario, no en el de la literatura adulta, donde es habitual, sino en el de la literatura infantil. No solo ellos están pensando en los cambios necesarios para mejorar la vida, hay otras personas, en otras latitudes, que han aceptado que el mundo se ha abierto, con los mass Medias y las TIC, y que han permitido ampliar la visión que los niños tienen de las cosas, de los otros, de la vida, de la muerte. Hay dos libros, que para este trabajo consideramos adecuados, que, en primera medida, muestran 
que sí es necesaria una educación para la muerte y que, en segunda medida, rompen con lo planteado por Bortolussi, no para decir que ella estaba equivocada, sino como una muestra de la evolución normal que la literatura infantil tiene, debido, evidentemente, a los cambios que tiene nuestro mundo. El primer título, El libro triste, es una magnífica obra de Michael Rosen, ilustrada por Quentin Blake, y el segundo título, Humo, es una obra de Antón Fortes, ilustrada por Joanna Concejo.

La obra de Michael Rosen nos presenta cómo se desenvuelve un hombre ante la muerte de su hijo. En su ausencia, de su ser más querido, la vida va perdiendo brillo, sentido, y solo va quedando un espacio gris, un exterior insignificante, que no le llena su vacío. A pesar de que en ocasiones pareciera abrirse una esperanza: "Pero a veces me sorprendo a mí mismo mirando cosas: gente en la ventana. Una grúa y un tren lleno de gente..." (Rosen, 2004) el libro nos devuelve toda su tristeza después de los recuerdos y la notoria falta de su hijo. La combinación entre narración e ilustraciones nos lleva a reconocer que, en primera medida, no es un libro para entretener. No existe un discurso de aventura, ni de metas y objetivos alcanzados satisfactoriamente. Tampoco pretende, como en la edad media, dar un discurso moralizante, que mantenga los valores de esta época. De igual manera, no funciona como guía, es decir, como didáctica, de lo correcto ante la muerte. Nada menos que eso. Se trata fielmente de una actitud de un hombre ante la muerte de su ser más querido. Una reacción que no quiere ir más allá de esa reacción. La historia nace en la tristeza de la muerte del hijo y termina en la tristeza de la muerte del hijo.

En efecto, el escritor de El libro triste no piensa en el niño como el destinatario que reconoce Bortolussi. Recordemos que para Bortolussi el destinatario en la literatura infantil es quien da las pautas para que el escritor haga su obra. Asimismo, para ella, el niño no posee las facultades para responder adecuadamente a algunas temáticas y es el escritor quien tiene que poner límites sobre su escritura (Bortolussi, 1987, pp. 67-68). Sin embargo, en el cuento no existe "un elemento de optimismo" y por más duro que parezca, no logra "terminar bien". El final del libro nos muestra a un hombre solitario, en la mesa de su casa, frente a una vela y un portarretrato, seguro de su hijo, con expresión acongojada, resignada, sometida al dolor. Tristeza que se fortalece al saber que el hombre acaba de recordar los momentos felices, tanto que le gustaban los cumpleaños junto a la gente, los pasteles llenos de velas (pastel que no existe en la última ilustración), en fin, la compañía.

Ahora bien, podría insinuarse que el libro está planteado para sobresaltar los recuerdos junto a los seres queridos; el tiempo pasado junto a ellos, las alegrías vividas. No obstante, consideramos que se tergiversaría la verdad de la obra. El niño se preguntará por qué solo el hombre puede recordar, y notará, pues, siempre después de que el hombre recuerda, que él está solo y muy entristecido. Podemos dividir el libro en cinco partes esenciales que se repiten con pequeñas variantes. La primera parte la componen las dos primeras ilustraciones, acompañadas de sus respectivos enunciados: en la primera el hombre está sonriente, pero leemos la tristeza en la frase que la acompaña, e, inmediatamente, en la segunda ilustración todo se torna gris y sin rostro. En la segunda parte, el hombre mira las fotos de su hijo divirtiéndose; la última está vacía y aparece su tristeza, en la mirada a un vacío, en un espacio gris, que se sustenta con actitudes extrañas que él toma y en una última caminata solitaria. En estas dos primeras, siempre, la narración que acompaña navega en la depresión. En la tercera parte busca la aceptación de su tristeza en la tristeza que ve en los demás o que lo rodea sin ser parte de él. La narración es un intento desesperado de hallar sentido a su tristeza en la tristeza ajena. Esta termina en un poema con una interpretación de la parte final acongojante: "Esta última frase significa que no quisiera estar aquí. Que quisiera desaparecer" (Rosen, 2004). La quinta, 


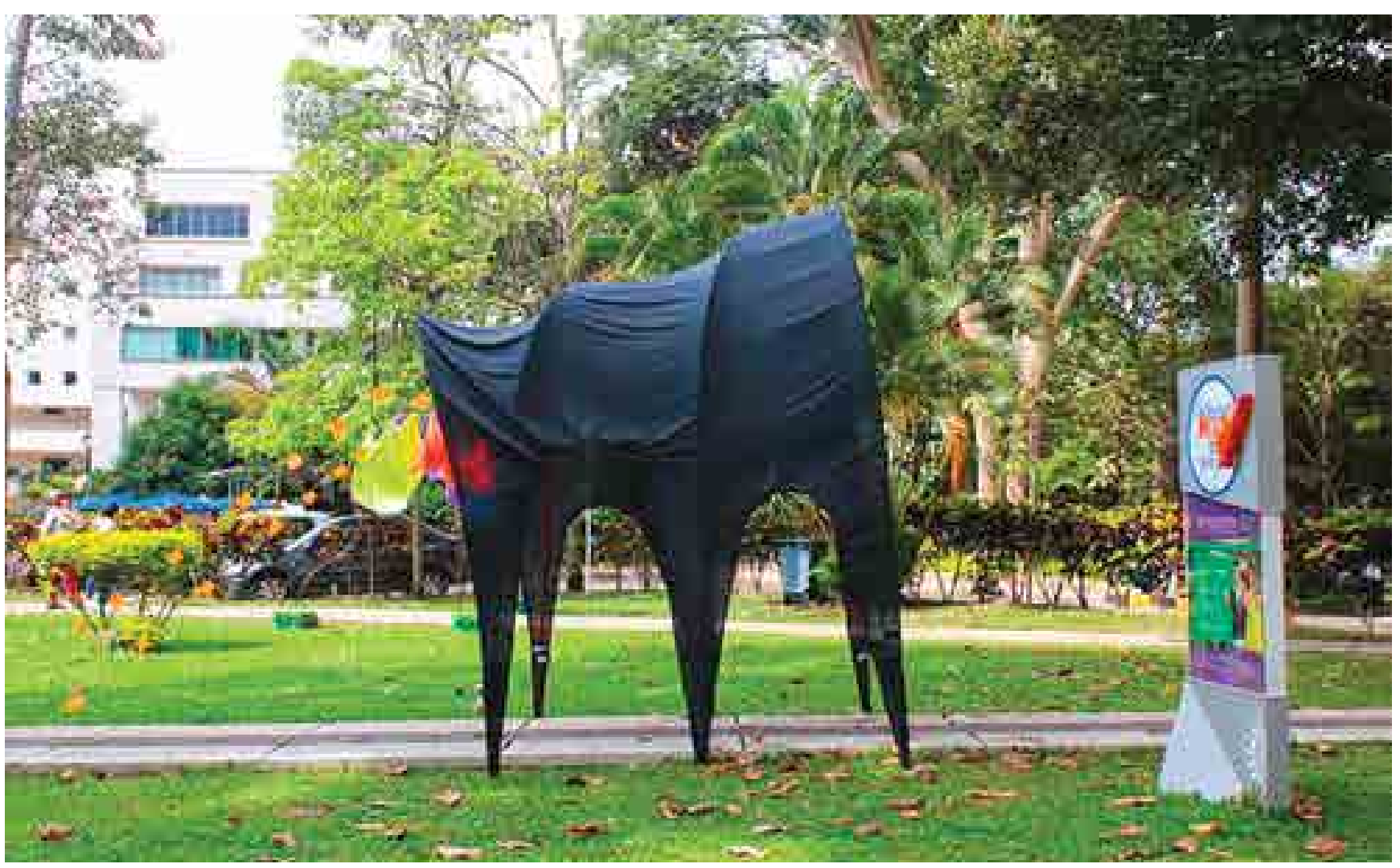

Proyecto Murciélago Indiana.

y última parte, comienza nuevamente con un brillo de luz, que florece desde los recuerdos, el de su madre, la risa de Eddi (su hijo muerto), el talento de Eddi, los juegos con Eddi, los cumpleaños, la compañía de Eddi y su familia; pero que se apaga con la última ilustración que ya hemos mencionado antes. Por lo tanto, el ejercicio de los recuerdos que acaban en su tristeza se repite y se sostiene, sin quebrantarse.

De tal manera, el niño que lea el libro de Rosen no necesariamente tendrá la experiencia de haber perdido un ser querido, nunca un hijo; probablemente conocerá la muerte por la televisión, por el Internet, por las películas o los cortometrajes o por algún cuento infantil del tipo que describe Bortolussi (supongo que alguna historia en donde muere un abuelo ${ }^{6}$ ). No obstante, el niño recibirá esta historia y la hará

6 Que también tendría relación con la cita que hemos puesto más arriba de Cortina y de la Herrán, puesto que termina siendo una imagen vedada de la realidad de la muerte. parte de su experiencia, quizá efecto contrario a lo pensado por Bortolussi.

Por su parte, Humo (Fortes, 2008) trata también la temática de la muerte, aunque su perspectiva, la situación que la produce, se diferencia de El libro triste. En el libro de Rosen la muerte de Eddi no sabemos cómo se produce, pero sí sabemos que sucede de manera abrupta y rompe con una vida establecida. Además, la muerte ya ha pasado y se ve desde los ojos de un adulto, su resultado, sus consecuencias. En cambio, en el libro de Fontes sí sabemos qué producirá la muerte (pues la muerte no acaece sino hasta el final, aunque vedada). Sabemos que se trata de un campo de concentración Nazi, el horror más grande que conoce el ser humano contemporáneo. Mientras en El libro triste el hombre sabe que su hijo ha muerto y vive en ello, en Humo el niño, que es el mismo narrador, desconoce su futuro y percibe los cambios de su rutina, de su entorno, y sabe que las cosas van mal por el llanto de su madre. Las 
ilustraciones que acompañan resaltan por su color ocre, que crean un entorno opaco, y algunos colores que resaltan detalles especiales, como el azul de la habitación que recuerda el niño y el agua que transportan en baldes. Las ilustraciones también muestran las sensaciones del protagonista, como en las imágenes desfiguradas, de la primera página, de los guardias, aves feas, de rostros humanos, vigilantes; o las ilustraciones que muestran dos cabezas, de rostros vacíos, sin cuerpos, entre las patatas crudas que les dan de alimento.

El niño nos va describiendo las situaciones: los estados de ánimo y las decadencias psicológicas y físicas de las personas que están encerradas. Descubrimos una primera impresión desoladora: "Encima del portalón de entrada veo un reloj grande, altavoces y focos. La luz me lastima los ojos. Los perros ladran, aúllan. En una hilera quedamos mamá y yo; papá, en otra" (Fortes, 2008, p. 4). El recibimiento en el campo de concentración implica inmediatamente una ruptura que irá acrecentando a medida que transcurre la historia. Asimismo, el cambio de condición que recalca el niño, entre la vida pintada de azul de los recuerdos y la realidad pintada de dureza y de verdad: "Nos toca en la casa número 48. Papá no está. Hay literas viejas de madera, con paja. Dormimos abrazados, apretados por los demás. Echo de menos mi habitación azul, pero no digo nada" (Fortes, 2008, p. 5). El lector infantil notará que hay una ausencia manifiesta, el padre que fue separado en otra fila, y también que el espacio físico no constituye la necesidad de cualquier niño. El espacio más que compartido es lleno de personas, amontonadas, incómodas. Poco a poco el niño descubre, por las palabras de su madre, que ni la ropa, que les han dado, pues les han arrebatado las suyas, es la adecuada: "A mamá el traje le queda grande y los zuecos la lastiman" (Fortes, 2008, p. 7); que serán expuestos a condiciones que el cuerpo sufre y que, en condiciones normales, nadie debería soportar: "Lo malo es estar tanto tiempo de pie al frío y a la nieve..." (Fortes, 2008, p. 7); descubre que es un lugar donde la tristeza de los niños no es posible y tendrá que atragantarse el dolor, absorberlo, tenerlo para él solo, pues quien lo demuestra no vuelve junto a sus seres queridos: "Nunca lloro, porque al bebé que lloriqueaba por la noche se lo llevaron, y su madre no para de gritar" (Fortes, 2008, p. 9). Descubre, por último, la necesidad de hacerse fuerte, aunque sin saber por qué debe serlo, siendo tan niño, ni mucho menos sabe que a pesar de su fortaleza el final seguirá siendo el mismo.

Humo nos va mostrando también el miedo que empieza a consumir al niño. Sus sueños son tenebrosos, con dragones, y la madre sabe que él empieza a sucumbir. La obra también nos presenta la violencia gratuita contra todos, incluso los niños: "Lo malo es cuando los soldados disparan o pegan con la culata del fusil" (Fortes, 2008, p. 21); la mirada de los niños hacia la muerte ajena, se vuelve cercana, y es clara como un manantial. Aunque pequeños, sienten que ellos podrían ser los próximos: "Peor es cuando nos llevan al patio y cuelgan a personas. Mamá me dice que cierre los ojos, que después sueño con dragones" (Fortes, 2008, p. 21). El trabajo pesado de la madre, sus escondidas para que no se lo lleven, las enfermedades, la debilidad de su amigo Vadío, las ilustraciones frías y certeras, los cuerpos mutilados de la penúltima página, en donde el guardia los manda a "duchar", la obscuridad y la desnudez de dos almas inocentes que pronto se entregarán a la nada del exterminio son las constantes de una obra real y sincera.

La muerte de ellos no se muestra. No obstante, el final abierto genera preguntas para cualquier niño: ¿Qué pasó con el papá?, ¿en dónde está la mamá?, ¿qué pasó con el niño?, ¿los otros eran malos?, ¿por qué los golpeaban?, ¿por qué son tan obscuras las duchas? Preguntas que apuntan directamente hacia la muerte. Reconocemos que el lector infantil, o adulto, acaba de hacer un recorrido a través de los ojos de un niño que desconoce, pero que igualmente muere. El lector experimenta el desconcier- 
to, el dolor, el miedo, la tristeza arrebatada, el camino hacia la muerte. Actualmente, con los mass media y las TIC, el niño accede a información de grandes tragedias sin necesidad de mediación. Los niños poco a poco acompañan la muerte de sus semejantes sin conocerlos. Su experiencia se ve superada constantemente por situaciones que en años anteriores eran pensadas no aptas para ellos. Humo muestra a los niños que no solo los viejos muy viejos mueren, que la muerte es un camino para cualquiera y que cualquier razón en últimas es legítima para la muerte, aunque en Humo las razones tampoco son claras para un infante. Tal como lo dice Cortina y de la Herrán, hay un tabú que se está rompiendo y que se hace imperante una reflexión profunda de los niños en torno a reconocer y reconocerse ante la muerte.

\section{Conclusiones}

Desde lo propuesto por Bortolussi, en su texto Análisis teórico del cuento infantil, como los límites de la literatura infantil ha habido muchos cambios en los escenarios tecnológicos y comunicativos. Cambios que han permitido, y hecho necesario, expandir la recepción de los niños porque su acceso a todo tipo de información se ha hecho más posible. La muerte ya no es un misterio, ni un suceso que solo sacude a las personas mayores. Los mass medias, las TIC, las armas de destrucción masiva han puesto en nuestra escena, diariamente y en masa, esta realidad. Esa realidad trágica, que Bortolussi consideraba inadecuada para la apreciación de los niños, está presente en nuestro siglo. Los límites de recepción levantados por la literatura infantil del siglo XIX y del XX están siendo transgredidos; lo que no quiere decir que los anteriores temas ya no son válidos e importantes y que los escritores deben erradicarlos de sus creaciones artísticas; asimismo, tampoco significa que los temas tabú, que empiezan a ser visibles para los niños, sean inconvenientes y deban ser devueltos a la oscuridad de la prohibición moral; sino que la transgresión de la literatura infantil, de dichos límites, evidencia el ritmo de transformación de nuestra existencia. Con El libro triste y Humo reconocemos una nueva etapa de la concepción literaria infantil, en donde los escritores amplían sus temáticas con la fe de que los niños de nuestra actualidad están más dispuestos a recibirlas y discutirlas, una apuesta arriesgada, pero necesaria; una nueva etapa donde la escuela debe comprometerse a replantear sus formas educativas, sus procesos de enseñanza y aprendizaje, sus temáticas centrales; comprometerse a preparar a los niños desde muy temprana edad en la muerte, en su posibilidad, en su cercanía, y en algunas de las formas en que puede aparecerse, no con el fin de crear traumas, sino de hacer posible una preparación emocional que no afecte el devenir de su existencia. Ante esta nueva etapa, la literatura infantil también se seguirá transformando, con el replanteamiento de sus bases temáticas, con nuevas posibilidades de presentación de sus historias; lo que conlleva, inevitablemente, una ruptura con lo que, en un momento anterior, pudo ser considerada su estructura. Esta ruptura ante la tradición será otra más incrustada en la historia, ni peor ni mejor que la anterior o que la próxima, y deberá concebirse como respuesta a las evoluciones propias de la humanidad.

\section{Referencias}

Aranguren, J. (1985). Ética. Madrid, España: Alianza.

Bortolussi, M. (1987). Análisis teórico del cuento infantil. Madrid, España: Alhambra.

Cortina, M., y de la Herrán, A. (2007). Fundamentos para una pedagogía de la muerte. Revista Iberoamericana de Educación, 2(41), 1-12.

Cortina, M., y de la Herrán, A. (2008). La educación para la muerte como ámbito formativo: más allá del duelo. Psicooncología, 5(2-3), 409-424.

Duarte, J. (2013). Infancias contemporáneas, medios y autoridad. Revista Latinoamericana de Ciencias Sociales, Niñez y Juventud, 11(2), 461-472. Recuperado de http://www. scielo.org.co/pdf/rlcs/v11n2/v11n2a02.pdf.

Fortes, A. (2008). Humo. España: OQO Editora.

López, R. (1990). Introducción a la literatura infantil. España: Universidad de Murcia, Secretariado de Publicaciones.

Marqués, P. (2012). Impacto de las TIC en la educación: funciones y limitaciones. Revista de Investigación, $N(\mathrm{~N})$, 1-15. Recuperado de http://www.3ciencias.com/wpcontent/uploads/2013/01/impacto-de-las-tic.pdf.

Rosen, M. (2004). El libro triste. Barcelona, España: Ediciones Serres. 